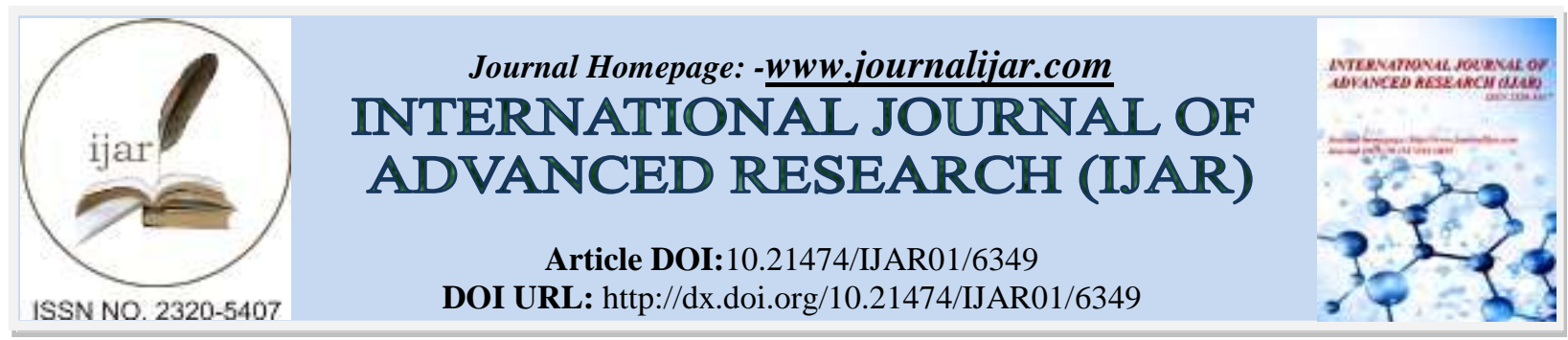

RESEARCH ARTICLE

\title{
PREVALENCE OF MALNUTRITION AMONG CHILDREN UNDER 5 YEARS IN THE MUNICIPALITIES OF 2KP (KÉROU,
} KOUANDÉ AND PÉHUNCO) IN NORTHERN BENIN.

\section{Marius Bio Bouko ${ }^{1}{ }^{*}$ Abdou Ganiou Yessoufou ${ }^{1}$, Justin Behanzin ${ }^{1}$, Abèbi Karimath Yessoufou ${ }^{2}$ and Alphonse Sezan ${ }^{1}$.}

1. Laboratoire de Biomembranes et de SignalisationCellulaire, Département de PhysiologieAnimale, Faculté des Sciences et Techniques, Universitéd' Abomey-Calavi, BP : 526 Cotonou, République du Bénin.

2. Clinique de PédiatrieetNéonatologie de Sènadé 06 BP 601 Cotonou, République du Bénin.

\section{Manuscript Info}

Manuscript History

Received: 19 November 2017

Final Accepted: 21 December 2017

Published: January 2018

Key words:-

Benin, emaciation, stunting, underweight, weaning practices.

\section{Abstract}

Malnutrition is the set of disorders / conditions resulting from the deficiency or excess of one or more essential nutrients. It is a public health problem in many developing countries. In order to reduce the prevalence of malnutrition in a community, it is important to describe the nutritional status of the community and to look for the determinants of this situation. In view of the damage caused by this pathology, we were interested in determining the prevalence of malnutrition among children under five in $2 \mathrm{KP}$ communes. It is a prospective, descriptive and analytical study in which we collected the anthropometric measurements of 600 children and submitted their mothers to a questionnaire. The results show that the three forms of undernutrition are still present with $64.8 \%$ of stunted children, $11 \%$ of underweight children and $2 \%$ of emaciated children. Moreover, the dietary diversity scores recorded among the surveyed households are mostly low. The factors identified as responsible are, among others, the non respect of the principle of exclusive breastfeeding, the bad practices of weaning, the diseases. In sum, the very high level of stunting is indicative of chronic food insecurity. It urges an awakening of consciousness of the different actors involved in the fight against malnutrition for an improvement of the nutritional status of children in $2 \mathrm{KP}$.

Copy Right, IJAR, 2018,. All rights reserved.

\section{Introduction:-}

Under-nutrition is responsible for more than one-third of all deaths of children under five. It weakens children and worsens the effects of diseases that strike them. Undernutrition is a public health problem in the developing world: 90\% of stunted children live in Africa and Asia (UNICEF, 2009). In Benin, 4.7\% of children aged 6 to 59 months suffer from wasting, including $0.7 \%$ of severe cases.

Atacora is the most affected department with $7.8 \%$ of emaciated children, which reflects a poor nutritional situation according to the thresholds established by the WHO (WHO, 2006). Underweight affects $17.3 \%$ of children under 5 in Benin. Atacora is one of the departments where this prevalence is very high at $22.5 \%$ (AGVSAN, 2009). At the national level, $37 \%$ of children aged 6 to 59 months suffer from chronic malnutrition, $12 \%$ of which are severe cases. In Atacora, the prevalence even exceeds the critical threshold of $40 \%$ or $42.8 \%$ (AVGSAN, 2009). This level 
of chronic malnutrition is considered high and indicative of chronic food insecurity. Indeed, according to the report of the Global Analysis and Vulnerability in Food Security (AGVSA, 2014), 48\% of households in the department of Atacora had inadequate food consumption that did not allow them to lead healthy and active lives while this problem affected only $23 \%$ of households nationally. In addition, Atacora is among the Departments with the highest rates of food insecurity (AGVSA, 2014). Also, it is not easy to see that all the strategies carried out on the ground to fight this scourge have remained vain because the prevalence of the various forms of malnutrition remain high in this zone.

In view of all the above, we proposed to evaluate the nutritional status of children under 5 years in three $(03)$ Atacora Municipalities: Kérou, Kouandé and Péhunco (2KP), to identify the determinants of these malnutritions in order to improve the nutritional situation of the populations.

\section{Material and Methods:-}

The study was conducted in the communes of Kérou, Kouandé and Péhunco (2KP) located in northwestern Benin and more precisely in the Atacora department (Figure 1). This is a prospective, descriptive and analytical study, which ran from July to October 2015, during which we collected the anthropometric measurements of 600 children under 5 years and submitted their mothers to a questionnaire. elaborated for this purpose. The size of the sample was determined from the Schwartz formula (1995). In the field, households are randomly determined in each district using the standard method. Demographic data for the identification of clusters in the area are provided by RGPH4 (2013)

\section{Anthropometric measurements:-}

The weight of the children was collected by means of a suspended scale of Salter WeghStonx type of $25 \mathrm{~kg}$ range divided by 100 grams. The height was taken using a $0.1 \mathrm{~cm}$ precision Sonatometer for all children. For children under two, the board has been placed horizontally on a flat surface parallel to the floor. For children 2 to 5 years old, the measurement was done while standing. Age was determined from the birth certificate extracts, and especially the children's health notebooks and mother's maternity notebooks or using the method based on the chronology of births socio-cultural events. Anthropometric measurements are used to characterize the nutritional status of the study population.

Data analysis: Nutritional Status Assessment: The P / T (Weight for Height), T / A (Age Size), P / A (Weight for Age) Indices were calculated based on WHO references (ONIS and al., 2006). Thus, there is respectively emaciation, stunting or underweight when P / T is below -2 ET, T / A is below -2 ET, P / A is below -2 ET of the reference median. Note that when Z-score is below -3ET, the associated malnutrition problem is considered severe. Dietary diversity score: The dietary diversity score of the child was calculated according to the construction of the MOURSI et al (2008) and Fanta (2006) score. Thus, children were classified in low dietary diversity (score 1-2), average (score 3-4) and high (score 5-6 and above).

Statistical Processing and Analysis of Data: Data processing was done using Excel, WHO Anthro® Version 3.2.2, 2011 and SPSS. The chi-square test in uni-varied analysis was used to look for an association between the various factors and the nutritional status of the children. The higher the chi2 value, the less significant the test $(\mathrm{p}<0,05)$.

Ethical considerations: The investigation was carried out after the authorization of the politico-administrative officials of the concerned Communes. The people surveyed gave their consent orally for their participation in the study.

\section{Results:-}

Of a total of 600 predominantly male children under 5 years (sex ratio 1.08), $2 \%$ were wasted, $64.8 \%$ were stunted and $11 \%$ were underweight. In addition, $33 \%$ of children have a low dietary diversity score, $38 \%$ an average score and $29 \%$ have a high diversity score.

The distribution curves of the surveyed population compared to the respective reference curves are shifted to the left for the T / A and P / A curves (Figure 3, Figure 4) and to the right for the P / T curve (Figure 2). The different chisquare tests have showed a significant relationship between weaning practices, diseases, dietary diversity of children and the three forms of undernutrition. 
Figure 1:- Geographic location of 2KP municipalities.
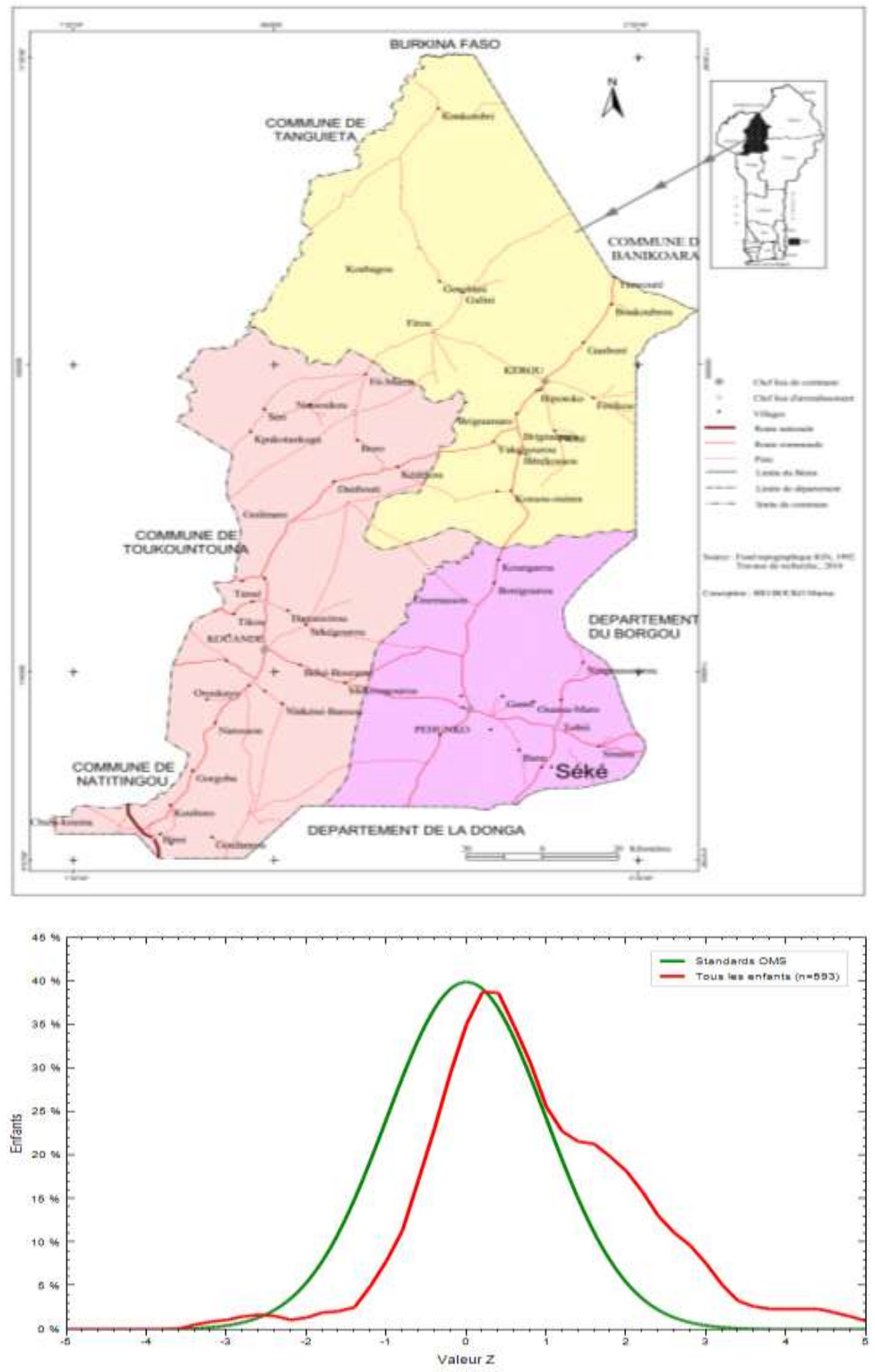

Figure 2:- Distribution of the Weight / Size (P / T) index in z-score relative to the reference population 


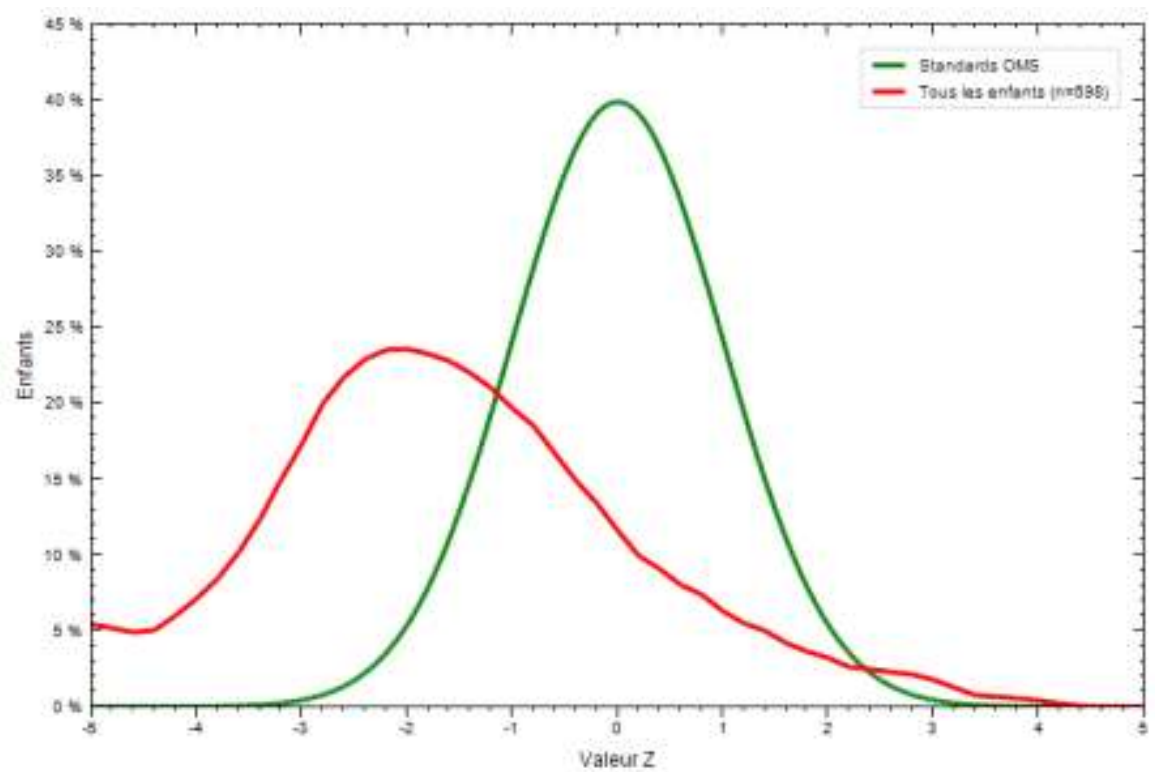

Figure 3:- Distribution of the Size / Age (T / A) index in z-score relative to the reference population

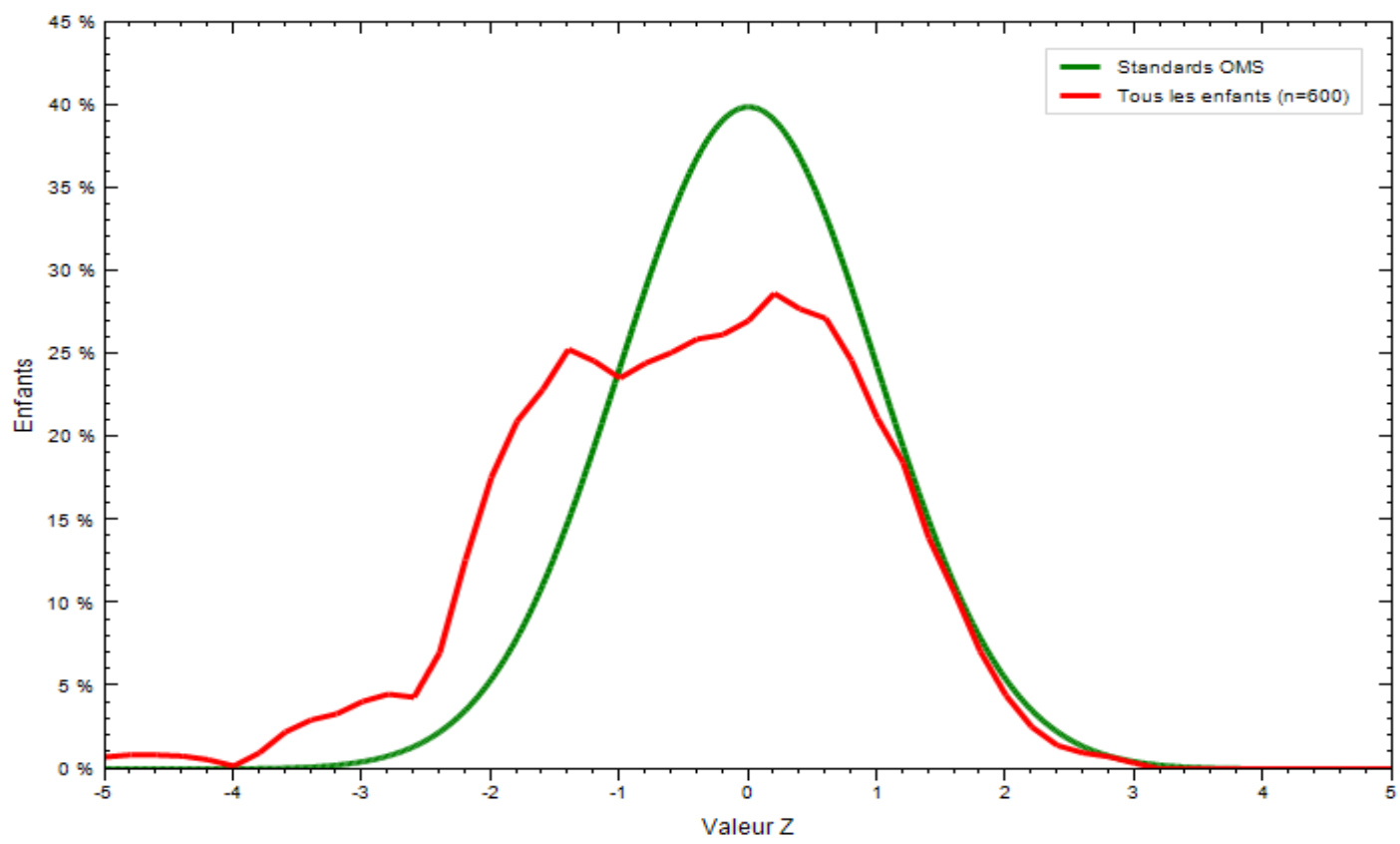

Figure 4:- Distribution of the Weight / Age (P / A) index in z-score relative to the reference population.

\section{Discussion:-}

\section{Nutritional status of the surveyed population:-}

The results show that $64.8 \%$ of children are stunted, $11 \%$ are underweight and $2 \%$ are wasted. These results are superior to those obtained by Yessoufou and al. (2014) in the Communes of the Pendjari Plain (Cobly, Materi and Tanguieta) regarding stunting. On the other hand, the results are inferior to those obtained by these authors in the same area for emaciation and underweight. This difference could be explained by the survey period and / or the degree of food insecurity in each area of the Atacora Department. Moreover, the results are superior to those of the EMICOV (2010) and SMART (2015) surveys carried out in the Atacora Department with regard to stunting on the one hand, and lower on both (02) other forms of undernutrition. According to the WHO (2006), the prevalence thresholds for each of three forms of undernutrition must be less than: $20 \%$ for Growth retardation, $5 \%$ for wasting 
and finally $10 \%$ for PI, which makes think of a critical situation with regard to stunting and poor for underweight. On the other hand, the nutritional situation for emaciation is acceptable in 2KP. Therefore, it is not useful to point out that the low prevalence observed at the level of wasting could be justified by the period of food abundance of the survey.

The comparison of the different Z-score P / A, T / A distribution curves with the respective reference curves, showed that these curves were shifted to the left compared to the reference curves, which indicates a less satisfactory nutritional state. in relation to that of the reference population evoking a tendency to a state of under-nutrition, as several authors have pointed out (Yessoufou and al., 2015; Yessoufou and al., 2016). On the other hand, the distribution curve Z-score $\mathrm{P} / \mathrm{T}$ is slightly shifted to the right at the reference curve, which is confirmed by a very low prevalence for this form of malnutrition in the study population.

\section{Factors involved in the nutritional situation of children:-}

A statistically significant association was observed between nutritional status and dietary diversity of children. This corresponds to the results obtained by several authors: Yessoufou and al. (2014) in the Pendjari Plain, Kennedy and al. (2007) in the Philippines and Laoda and al. (2009) in Burkina Faso. On the other hand, other studies have revealed that there is no relationship between nutritional status and dietary diversity such as that of Abomey-Calavi in southern Benin (Yessoufou and al., 2016) and that carried out in Senegal ( Nyambose, 2005). These differences could be explained by the socio-economic characteristics of the populations in the survey area and / or the period during which the survey was conducted. Moreover, a significant relationship was established between the three forms of undernutrition and the disrespect of the principle of exclusive breastfeeding during the first six months of life on the one hand, and diseases on the other hand. Indeed, breastfeeding is a safe and hygienic source of sufficient energy, nutrients and liquids. Failure to respect this principle by mothers could also expose children to the most fatal diseases involving different forms of malnutrition, as several authors have pointed out (Barthélémy, 2002, Koné, 2008, Yessoufou and al., 2014).

\section{Conclusion:-}

In sum, the very high level of stunting is indicative of chronic food insecurity in the $2 \mathrm{KP}$ municipalities. This situation calls on all actors to enhance the benefits of appropriate actions aimed at considerably reducing the rate of this scourge.

\section{References:-}

1. AGVSAN (Analyse Globale de la Vulnérabilité, de la Sécurité Alimentaireet de la Nutrition) (2009). Pam/insae. République du Bénin. $168 \mathrm{p}$

2. Agvsa (analyseglobale de la vulnérabilitéet de la sécuritéalimentaire) (2014).Pam/insae. République du bénin. 146 p.

3. Barthelemie 1. (2002). Approched' identification des élémentsconcourant à l' apparitiond' une malnutrition protéino-énergétique en guyanefrançaise. Thèse de médecine, université de nantes, $162 \mathrm{p}$.

4. Emicov (enquêtemodulaireintégrée des conditions de vie) (2010). Insaerépublique du bénin, rapport préliminaire, 69 $\mathrm{p}$

5. Fanta. (2006): working group on infant and young child feeding indicators. Developing and validating simple indicators of dietary quality and energy in take of infants and young children in developing countries: summary of findings from analysis of 10 data sets. Washington, dc: the food and nutrition technical assistance project and academy for educational development, 192-199.

6. Kennedy G.L., Pedro M. R., Seghieri C., Nantel G., Brouwer I. (2007). Dietary diversity score isa useful indicator of micronutrient intake in non-breast- feeding filipino children. The american society for nutrition j.nutr.137:472-477

7. Kone M. (2008). Stratégies des ménages et malnutrition infantile dans la région de madarounfa. Afriquecontemporaire, 1(225) : 161-197.

8. Loada M., Nikiema L. (2009). Enquêtenationalesurl' insécuritéalimentaireet la malnutrition (eniam). Rapport définitif ; république du burkina-faso, $193 \mathrm{p}$

9. Moursi M., Martin-prevel Y., Eymart-duvernay S., Capon G., Maire B., Delpeuch F. (2008) assessment of child feeding practices using a summary index: stability over time and association with child growth in urban madagascar.an j clin nutr.87:1472-1473

10. Nyambose B. (2005). A young child feeding index is not associated with either height- for-age or height valor city in rural senegalese children. Journal of nutrition.135: 457- 464.

11. OMS. (2006). Normesoms de croissance de l' enfantlongueur/taille pour l'âge, poids pour l'âge, poids pour la longueur, poids pour la tailleetindice de quételet pour l'âge. Méthodesetélaboration. Département nutrition, santé etdéveloppement. $11 \mathrm{p}$. 
12. De onis M, Onyango AW, Borghi E, Garza C, Yang H ( 2006). For the who multicentre growth reference study group. Comparison of the world health organization (who) child growth standards and the national center for health statistics, who international growth reference: implications for child health programmes. Public health nutrition; 9: 942-947.

13. RGPH 4 (2013). résultatsprovisoire du quatrièmerecensementgénéral de la population et de l' habitat, insae, république du Bénin $4 \mathrm{p}$

14. Smart (suivi et evaluation normalisés des phases de secours et de transition). (2006). Measuring mortality, nutritional status and food security in crisis situations: smart methodology version 1. Standardized monitoring and assessment of relief and transitions. $109 \mathrm{p}$

15. Unicef (fonds des nations unies pour l' enfance). (2009). Suivre les progrèsdans le domaine de la nutrition de la mère : New york. 119 p.

16. Yessoufou A. G; Ahopke M.; BehanzinJj.; Kountori R.; Senou M.; Sezan A. (2014). Prévalence de la malnutrition aigüe chez les enfants de moins de cinqansdans la plaine de pendjari au nordouest du bénin ; j. Rech. Sci. Univ. Lomé ( Togo) série a 16(3):62-78

17. Yessoufou A. G. ; Yessoufou k. A. ; gbaguidi b. ; sezan a. ( 2015). Evaluation anthropométrique de l' étatnutritionnel des enfants de 0 à 59 moisreçusàl' unité de vaccination du chr.Lomé. Commune (togo) j. Rech. Sci. Univ. Lomé (Togo), serie a 17(1):21-32

18. Yessoufou a. G. ; Vinou A. Y. ; Gbaguidi B. ; Affognonj. K. ; Baba-Moussa L. ; Sezan A. (2016). Diversity in food and nutritional status in children from 6 to 59 months in the municipality of abomey-calavi south east of benin(west africa) int. J. Of advanced re 4(2):594-600. 